\title{
ARTICLE \\ Velocity of Money in Ethiopia
}

\section{Kedir Bekeru Genemo*}

Economic Modeling and Policy Analysis Directorate, National Bank of Ethiopia, Addis Ababa, Ethiopia

\section{ARTICLE INFO}

Article history

Received: 11 August 2021

Accepted: 24 September 2021

Published Online: 30 September 2021

\section{Keywords:}

LOWESS

Credible interval

Prior

Posterior

\begin{abstract}
Velocity of money is an important instrument used to measure the monetary target and quality of monetary policy. Referencing the trends in the money velocity, mainly in the short term, will have a paramount effect in determining the trends in real money growth. This study investigates the main causes of money velocity in Ethiopia using time series data for the period 1974/75 to 2015/16. A regression with Bayesian estimation and nonparametric Locally Weighted Scatterplot Smoothing (LOWESS) methods were used to analyze the data. Variables such as credit, real interest rate, real exchange rate and real per capita income were included as potential determinants of money velocity. The findings of using non-parametric LOWESS methods show an upward trends in the velocity of money since 2002 and downward trends before 2002, indicating the existence's of prudent monetary policy in Ethiopia after 2002. The result also shows a positive effect of real exchange rate and credit, whereas income per capita and real interest rates have a negative effect on velocity of money in Ethiopia. Hence, this paper recommends that, the policy to encourage sustainable economic growth and increase in interest rate would be beneficial to reduce velocity of money.
\end{abstract}

\section{Introduction and Background of Study}

In the studies of the relationship among money, output and price, the money velocity is assumed to be stable in the short-run. However, if the change in velocity of money could be significant in the short-run, the money growth indicator may add significant noise to monetary analysis. Consideration of velocity of money in setting monetary policy is important when financial markets are underdeveloped, choices of monetary instruments are limited, interest rates are ineffective, and monetary operations largely depend on targeting money aggregates ${ }^{[1]}$. Against this preview, in Ethiopia, a working assumption is that velocity is declining by 2 percent each year ${ }^{[4]}$. This could lead to the setting of aggregate money growth targets that are higher than the desired growth rates of nominal output.

Several researches have linked the determinants of demand for money to search the predictability of velocity of money. It has shown that income and inflation were significantly determine demand for money ${ }^{[10]}$, while the other also shows that it is more of inflation that determine demand than income and setting the monetary target needs to account for volatility as well ${ }^{[11]}$. This might be due to the fact that the increase in money velocity and the fluctuating market risk is increasing the importance for accounting for velocity of money to calculate the monetary target ${ }^{[4]}$. Substantial evidence shows that factors determin-

*Corresponding Author:

Kedir Bekeru Genemo,

Economic Modeling and Policy Analysis Directorate, National Bank of Ethiopia, Addis Ababa, Ethiopia;

Email:keder.beker@gmail.com 
ing money demand such as output and change in general price are also important in determining money velocity and, however, it also highlights that money velocity draw mixed picture about its prediction benefit in calculating the monetary target in the policy of targeting money as an intermediate policy to stabilize macro economy.

Most of the literature has focused on the determinant of money velocity, and again their evidences are encouraging ${ }^{[6,9,12,13]}$. Moreover, given the locally specific nature of monetary velocity, evidence is difficult to compare across cases and there is no agreement regarding the determinants of velocity of money. The issues of estimation methods, the variety of measuring velocity of money, the use of unstandardized observation in the methods were some of the factors contributed the disagreements on the determinants of monetary velocity.

This paper is designed to contribute to the literature on the determinants of velocity of money in Ethiopia. The factors that determine the velocity of money were closely examined. Some of potential estimation problems were addressed using Bayesian estimation and non-parametric Locally Weighted Scatterplot Smoothing (LOWESS). The analysis is drawn on the time series data collected from National Bank of Ethiopia (NBE) and the soundness of the factors presented by this paper relayed significantly on the analysis of priori information in determining posterior information.

This paper is organized in to four sections. The first section is introducing the paper, the second section is explaining about the methods of estimation; the third section is producing the analysis and makes discussion, and fourth section is about conclusion.

\section{Material and Methods}

\subsection{Data Type and Sources}

This study has used time series data collected from National Bank of Ethiopia and spanned from 1974/75 to 2015/16. The main variables are velocity of money, real per capita income, real interest rate, credit to output ratio and real effective exchange rate. To estimate the model and examine the statistical significance of the explanatory variables on velocity of money, multiple regressions with Bayesian estimation was employed.

\subsection{Model Specification}

The theoretical modern quantity theory specifies that the velocity function depends on the measure of output and change in general price. The rapid growth of institutions with technologically advanced payment and settle- ments system, especially entrenched banking system, also affects the way people conduct their economic transactions ${ }^{[5]}$. Hence, financial indicators should therefore enter the velocity function along with measures of output and change in general price. In this paper, inflation (change in general price) is captured by real interest rate. In the light of the theoretical and empirical discussion, the researcher proposes the following model for estimation of velocity equation.

$\mathrm{V}=\mathrm{PY} / \mathrm{M}=\mathrm{Y} /(\mathrm{M} / \mathrm{P})=\mathrm{Y} / \mathrm{Md}(\mathrm{RI}, \mathrm{PC}, \mathrm{CY}, \mathrm{RE})$

Where

$\mathrm{V}$.... velocity of money

PC... Real per capita income

CY... Credit to GDP ratio indicator for Financial Developments

RI......real Interest Rate

RE..... real effective exchange rate

While many agreed that income is one of the most important variables affecting movements in velocity, they do not all share the same view on the nature of the relationship between them. PC represents real income per capita. The way per capita income affects velocity depends upon income elasticity of demand for money. If it exceeds one, there will be a negative impact on per capita income on money velocity and vice versa ${ }^{[6]}$. The sign of association between $\mathrm{V}$ and PC depends on the phase of economic development, particularly the financial development ${ }^{[2]}$. At the earlier phase of economic development, the velocity may decrease with higher growth of output but at a later stage (phase), it may become positively correlated with output growth. The reason is that, at the initial stage of economic development there is increasing monetization, improvement of banking system and fast expansion of monetary transactions that leads to higher demand for money creating money velocity to fall down. At the advanced stage of development branded by transaction efficiency, financial modernization and technological development that guarantee the accessibility and use of money substitutes and provide a variety of money substitutes reduce the demand for money, which makes $\mathrm{V}$ boost up. Therefore, $\mathrm{PC}$ expected negative or positive sign.

Changes in the financial environment, both in developed and developing economies can also be expected to exert an influence on velocity. The behavior of economic units can be affected by changes in financial regulations, a wider range of financial institutions and assets, the spread of bank offices, the introduction of deposit insurance and credit cards, new techniques of cash management, etc. The psychological impact of these factors may be difficult to Operationalizing in a single variable. A common approach is to use the Credit to GDP ratio as an index of financial 
development or financial sophistication. This variable should have a positive or negative effect the velocity of money ${ }^{[8]}$.

Movements in the exchange rate can also affect velocity. This can be indirect through its impact on inflation. In a situation where confidence in the domestic and/or external value of the local currency is waning residents may seek to substitute foreign currency for local money. Real effective exchange rate and velocity of money expected to have positive relationship through inflation. Again, the real interest rate entails to some sort essence of inflation expectation and nominal interest rate. Moreover, increase in real interest rate may be due to increase in nominal interest rate or decrease in inflation and of is closely related to the velocity of money. When interest rate measure the opportunity cost of holding money it is expected to be positive since substitution can occur between money and alternative financial assets, an increase in the rate of interest contributes to a higher cost of holding money, and therefore, velocity increases ${ }^{[2]}$. Alternatively, if a rise in real interest rate measure decrease in price levels it is expected to have negative effect. Therefore, RI expected to have a negative or positive association with velocity.

Bearing these views the paper going to estimate the following model:

$V_{t}=\beta_{0}+\beta_{1} P C_{t}+\beta_{2} R I{ }_{t}+\beta_{3} C Y_{t}+\beta_{4} R E_{t}+\varepsilon_{t}$ (2)

$\beta 0, \beta 1, \beta 2, \beta 4$ are constant coefficient and $\mathrm{E}_{\mathrm{t}}$ is random disturbance term and other variable are as explained before.

\subsection{Estimation Methods}

\subsubsection{Unit Root Test}

Time series data on most economic variables are not stationary at level. A regression of non-stationary variables give spurious or inconsistent regression, which gives very high $\mathrm{R} 2$ due to time trend, that may lead to invalid statistical inferences ${ }^{[3]}$. In exploring effect of explanatory variable on income velocity of money, the first step is examining the statistical properties of time series data. Particularly, to find the order of integration of order $d$, written $\mathrm{I}(\mathrm{d})$ if it needs differencing $\mathrm{d}$ times to achieve stationary. Augmented Dickey-Fuller (ADF) test is performed to check the order of integration i.e. whether the variable are stationary at level or change.

\subsubsection{Bayesian Estimation}

Bayesian multiple regression models include specifications of the prior distributions for parameters. Prior specification may be conjugate or diffuse. If prior distributions are formulated with very small variances so that the prior knowledge strongly influences posterior distribution of the parameters in the model, then they are called informative priors. On the other hand if the priors are formulated using large variances they may have very little effect on the posterior distributions thus they are called diffuse priors ${ }^{[9]}$. In any way a very important issue is selection of priori information for which in this paper ordinary least square estimate is used. A population model for multiple regression models that relates the response variable Y to P-1 predictor variables is written as

$$
V_{t}=X \beta+\varepsilon
$$

Where $\mathrm{V}$ is response variable i.e. income velocity of money.

$\mathrm{X}$ is the known covariate, $\beta$ are the unknown parameter and $\mathrm{E}$ random error with variance $\delta^{2}$.

Since we do not know the values for $\theta\left(\delta^{2}, \beta\right)$ we will need to estimate them based on our data using Bayesian estimation, assuming that unknown parameter are random unlike frequenters approach. When both $\delta^{2}$ and $\beta$ are unknown we take the joint posterior distribution, after that we integrate to each parameter (i.e. find the marginal distribution of each parameter). However, this may be difficult in practice as the posterior density may be difficult to derive and integrate.

In fact, for many interesting models, it is unfortunately not possible to evaluate the moments and quintiles of the posterior $\mathrm{p}(\theta / \mathrm{v})$ analytically. In general, we are only able to numerically evaluate the prior distribution, $p(\theta)$ and the likelihood function $\mathrm{p}(\mathrm{v} / \theta)$. Nowadays, the integrals involved in Bayesian analysis are usually evaluated using numerical simulation methods known as Markov-chain Monte Carlo simulation. The simulation process needs burn in (i.e., run for long enough that the posterior distribution reaches a steady state that is independent of the starting values of parameters) and thinning. The mean of this probability density function is the point estimate of parameter $\beta^{[9]}$.

\section{Results and Discussion}

\subsection{Descriptive Analysis}

With aiming to analyze time series data mainly to identify, to describe the fundamental structure and to determine a suitable model to fit the data, the trends using Locally Weighted Scatterplot Smoothing (LOWESS) have been shown. The Figure 1 below shows the trend of the income velocity of money, real interest rate, per capita income, real exchange rate, and currency to GDP ratio in 
Ethiopia to see some insight portrayed from the graph. Again summary of statistic on these variables were explained in Table 1. It is observed that, the minimum money velocity is 2.412 and maximum is 7.189 , but on average, it is around 4. Again 50 percent of income velocity of money lies above 3.519 and 25 percent of income velocity lies above 4.027 .

Table 1. summary statistics for each variable under study

\begin{tabular}{|c|c|c|c|c|c|c|}
\hline summary & year & V & PC & RI & RE & CY \\
\hline Min. & 1975 & 2.412 & 294.2 & 0.512 & 93.58 & 21.54 \\
\hline 1st Qu. & 1985 & 2.996 & 387.5 & 0.07802 & 114.08 & 41.77 \\
\hline Median & 1996 & 3.519 & 802.1 & 0.02458 & 163.29 & 48.78 \\
\hline Mean & 1996 & 3.843 & 2450.2 & 0.03867 & 156.98 & 52.78 \\
\hline 3rd Qu & 2006 & 4.027 & 1663 & 0.04207 & 184.5 & 59.18 \\
\hline Max. & 2016 & 7.189 & 16572 & 0.19079 & 284.5 & 92.39 \\
\hline
\end{tabular}

Source: R- output on data from National Bank of Ethiopia

The LOWESS method was aimed to bring robust locally weighted observation and scatter plot smoothing for both equal-spaced and non-equal-spaced data. It is a data analysis method for making a "smooth" set of values from a time series observation, which has been tainted with noise. This method is an improvement over least squares smoothing which assumes when the data are equally spaced. In LOWESS smoothing method, the size of the smoothing window can vary from zero to one. The default window size is 0.1 which indicates that smoothing window has a total of width 10 percent over the time. By default, the LOWESS smooth command executes a weighted linear least squares fit of the points in the current data window ${ }^{[3]}$.

Its simplistic form is:

$$
\min _{\beta 0, \beta 1} \sum_{J \varepsilon N} W_{j}\left(Y_{j}-\left(\beta_{0}+\beta_{1} X_{j}\right)^{2}\right.
$$

Where $\mathrm{Y}$ is response variables or variable of importance and $\mathrm{X}$ is time period and $\mathrm{W}_{\mathrm{j}}$ is weight.

Form the Figure 1 the fit of locally weighted regression smoothing observed. The smoothing span used is $20 \%$, $30 \%$, and $50 \%$ for each line. At $50 \%$ spanning (the red line) the income velocity of money decreases from 19751993 persistently then constant from 1994-2003 on slightly decreasing, and then increased from 2004-present on decreasing rate as well. The actual decreasing of income velocity of money before 1993 and increasing after 2004 seems entails that large money injection before 1993 and low money injection after 2004 respectively when it compared to the income product that money used to carry out. The LOWESS line also showed that there is no outlier affected the line fit for income velocity of money, but the line is a bit similar to up word parabola in which the mini- mum is around 3.0.

Again, it has observed that per capita income, currency to GDP ratio and consumer price index slightly increased over time, while real Effective exchange rate declined over time. However, any of the covariate under study showed quadratic or any other form of the data. Hence one can have confidence to analysis with linear model because all the covariate shown exclusively with LOESS smoothing does not shown us any non-linearity in the data, in addition to quadratic or any other parabolic effect of variable form. Further investigation of the effects and relationships of those variables have on income velocity of money can be seen in Bayesian model without any assumption about the quadratic or parabolic effect of covariate. Now the question is what contributes to the decreasing or increasing of income velocity of money in Ethiopia, which can be answered by the econometric analysis in following content.
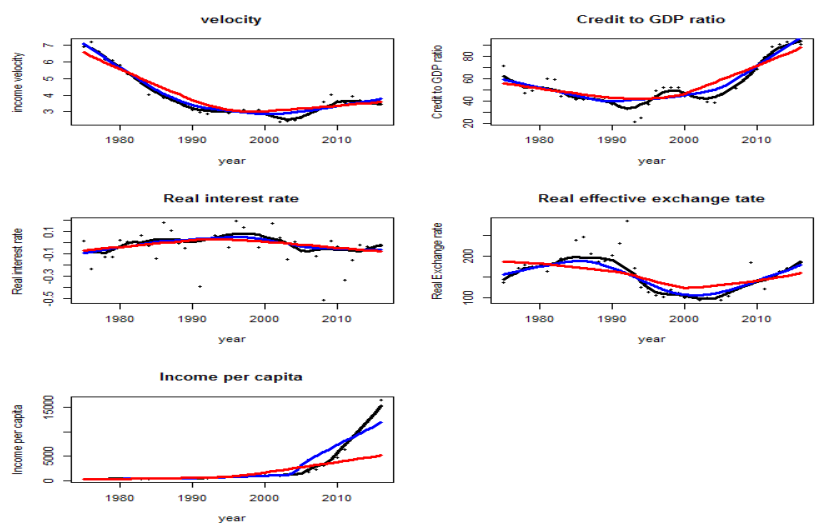

Figure 1. trends and LOWESS estimation of some selected variables in Ethiopia

Source: computation with R- on data from National Bank of Ethiopia

\subsection{Econometric Estimation Result}

\subsubsection{Unit Root Test Result}

Table 2 presents the results of unit root test using ADF test at level and at first difference. The results clearly show that the null hypothesis of "there is a unit root" in the level cannot be rejected at different lag. However, the first differencing of observation resulted in the series to be stationary. Finally we able to conclude that all of the variables are non-stationary with and without including test equation specifications through ADF test, and found stationary after first differencing or they are integrated of order one (.i.e. I(1)). 
Table 2. unit root test using ADF

\begin{tabular}{|c|c|c|}
\hline \multirow{2}{*}{ Variables } & ADF test statistic & ADF test statistic \\
\cline { 2 - 3 } & At level & At first difference \\
\hline V & -1.4994 & $-5.3970^{* * *}$ \\
\hline CY & -1.5993 & $-4.4345^{* * *}$ \\
\hline PC & 2.2164 & $-2.1988^{* * *}$ \\
\hline RI & -1.6742 & $-5.8719^{* * *}$ \\
\hline RE & -0.8184 & $-4.7222^{* * *}$ \\
\hline
\end{tabular}

Note: $* * *, * * *$ indicates rejection of the null hypothesis of a non-stationary at $1 \%$ and $5 \%$, and $10 \%$ levels of significance (critical test: -4.440739 at $1 \%,-3.632896$ at $5 \%,-3.254671$ at $10 \%$.

\subsubsection{Estimation of Model}

As it explained in detail under methods, using priori distribution of OLS and the likelihood function of parameter given the data, the posterior distribution estimated. After which sample simulation were used by Gibbs sampling method from MCMC pack package. The summary of result displayed in the Table 3.

From Figure 2 it depicted the stability of coefficient so that, the paper can positively interpret the result because of the plot showed the estimated coefficient on average clearly indicate symmetrically under normal curve. From the estimated model, the currency to GDP ratio which is a proxy for financial developments (financial environment), real per capita income, real exchange rate and real interest rate are the main determinants of income velocity of money because they are statistically significant.
Changes in the financial environment in Ethiopian economy posed positive effect on income velocity of money which might be due to the improvements in the access to cash, such as ATM cards or demand deposits that earn interest, such as interest-paying checking accounts, reduced the demand for money and increased bank branch. Since these payment substitutes a means of payment without the need to hold the money itself and it leads to increase in money velocity. A percent change in financial environment leads to about 0.077 increases in Velocity of money. This result is supported empirically ${ }^{[8]}$ and theoretically ${ }^{[7]}$.

Moreover, income per capita found to have a negative effect on income velocity of money. It is argued that at the initial stage of economic development there is increasing monetization, improvement in banking system and fast expansion of monetary transactions which contributes to the higher demand for money is pressuring money velocity to fall down ${ }^{[6]}$. A percent change in income per capita leads to about 0.0003 decreases in Velocity. Again, real interest rate is found to have negative and statistically significant effect, realizing a decrease in real interest rate due to increase in price affect velocity of money in Ethiopia which is in line with the literature ${ }^{[2]}$. It's found that, there is a positive relationship between real effective exchange rate and velocity of money. A percent increase in real effective exchange rate leads to about 0.008 percent increases in velocity. It means that the appreciation of the real effective exchange rate causes the income velocity to increase as the

Table 3. Bayesian Estimate of the Model

\begin{tabular}{|c|c|c|c|c|c|c|c|c|c|}
\hline \multirow{2}{*}{ Coefficient } & \multirow{2}{*}{ Mean } & \multirow{2}{*}{ SD } & \multirow{2}{*}{ Nä̈ve SE } & \multirow{2}{*}{ Time series SE } & \multicolumn{5}{|c|}{ Confidence interval } \\
\cline { 6 - 10 } & & & & $2.5 \%$ & $25.0 \%$ & $50.0 \%$ & $75.0 \%$ & $97.5 \%$ \\
\hline intercept & -0.7932 & 0.6833 & 0.0068 & 0.0068 & 0.0520 & 0.0693 & 0.0779 & -0.3444 & 0.57124 \\
\hline CY & 0.0778 & 0.0128 & 0.0001 & 0.0001 & 0.0520 & 0.0693 & 0.0779 & 0.0863 & 0.102113 \\
\hline PC & -0.0003 & 0.0001 & 0.0000 & 0.0000 & -0.0005 & -0.0004 & -0.0003 & -0.0003 & -0.00022 \\
\hline RI & -0.3255 & 0.7556 & 0.0076 & 0.0076 & -1.7872 & -0.8424 & -0.3323 & 0.1821 & 1.183025 \\
\hline RE & 0.0088 & 0.0028 & 0.0000 & 0.0000 & 0.0033 & 0.0069 & 0.0088 & 0.0106 & 0.014231 \\
\hline sigma2 & 0.8490 & 0.1911 & 0.0019 & 0.0021 & 0.5520 & 0.7121 & 0.8219 & 0.9548 & 1.293146 \\
\hline
\end{tabular}

Source: R- output on data from National Bank of Ethiopia

Table 4. Summary of output

\begin{tabular}{|c|c|c|c|c|}
\hline coefficient & Mean & SD & $2.5 \%$ & $97.5 \%$ \\
\hline intercept & -0.7932 & 0.6833 & 0.0520 & 0.0520 \\
\hline CY & 0.0778 & 0.0128 & -0.0005 & $0.1021134^{* *}$ \\
\hline PC & -0.0003 & 0.0001 & -1.7872 & $0.0002246^{* *}$ \\
\hline RI & -0.3255 & 0.7556 & 0.0033 & $0.0142309 * 25$ \\
\hline RE & 0.0088 & 0.1911 & 0.5520 \\
\hline
\end{tabular}

** shows significance level at 5 percent

Source: Author compiled from Bayesian output 

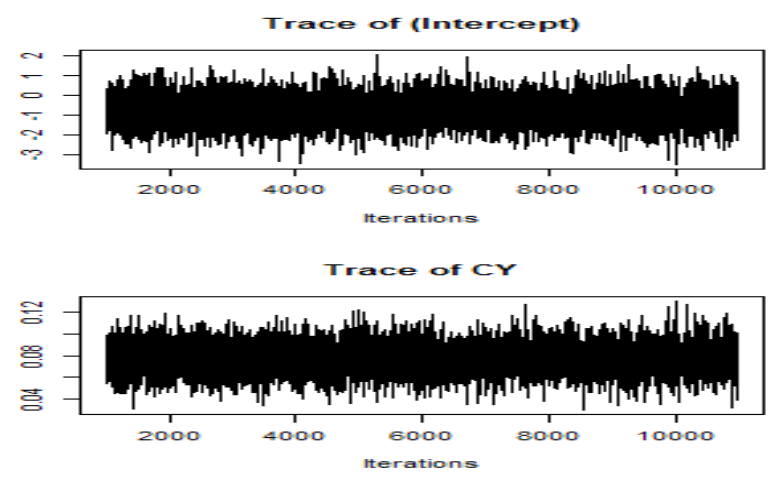

Trace of PC

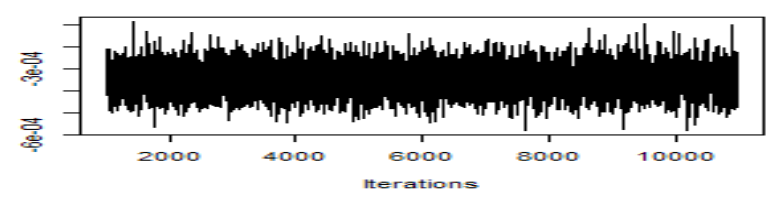

Trace of RI

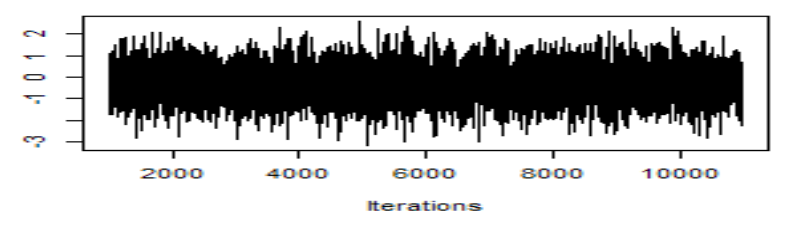

Trace of RE

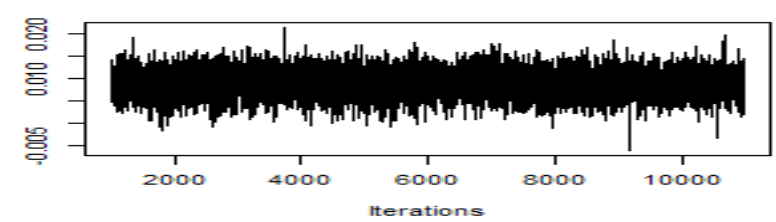

Trace of sigmaz

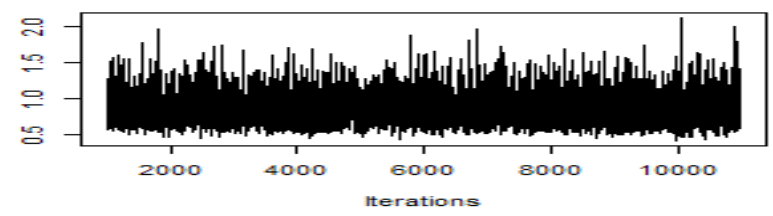

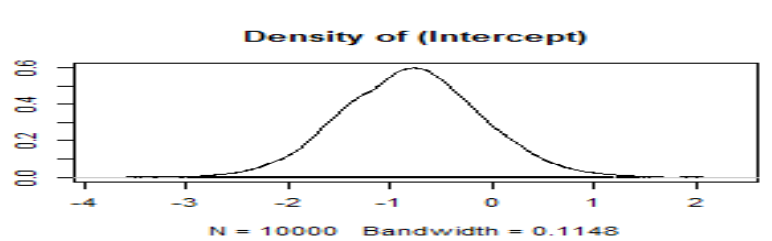
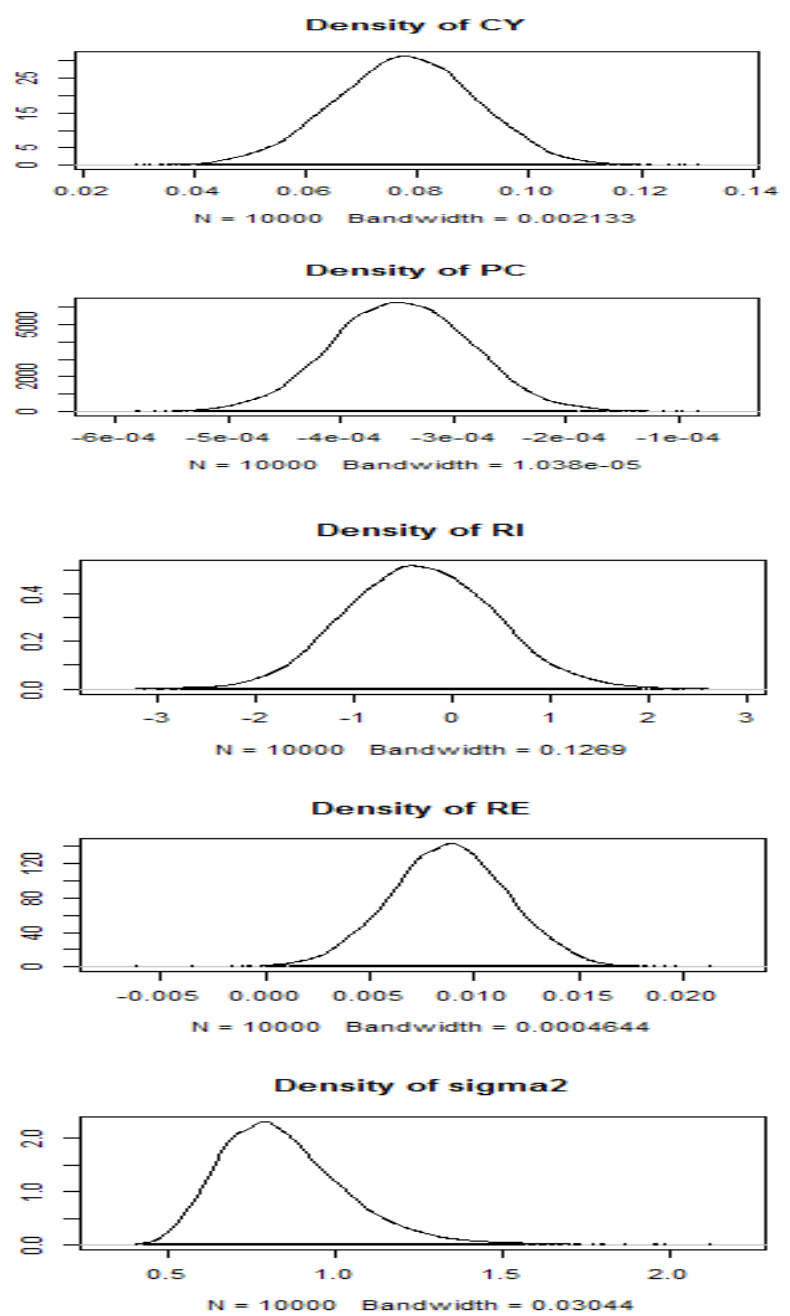

Figure 2. plot of the posterior distribution of parameter under estimation

Source: R- output on data from National Bank of Ethiopia

domestic portfolio holders readjust their portfolio in favor of foreign assets. Some literature found the reverse ${ }^{[2]}$.

Figure 2 plot shows the traces of the parameters on the left, each with different chain, all chain to converge to similar values (i.e. no divergence in the values on the right side of the plot). On the right side of the plot are the posterior distributions of the parameters. This is the key information this paper found from Bayesian regression analysis. Based on this figure we can confidently improve symmetricity of the regression parameter under the normal curve. Hence, there is no skewness of distribution of observation in each variable and the credible intervals in which the coefficient exists under the model were ex- plained well.

\section{Conclusions}

This study investigates the main causes of money velocity in Ethiopia using time series data for the period $1974 / 75$ to $2015 / 16$ by using Bayesian estimation and non-parametric locally weighted least square smoothing method. The resulting models were diagnosed for outlier and symmetricity for Bayesian model. The results show that velocity of money was associated with changes in the financial environment, per capita income, real exchange rate and real interest rate in the economy. In fact, finan- 
cial environment depends on increase in bank branch, interest-paying checking accounts, which has reduced the demand for money, contributing to velocity of money in Ethiopia. The increased income per capita resulted in increasing in public consumption has also contributed to decreasing rate of velocity of money. It is argued that Per capita income is associated negatively with velocity of money when income elasticity of money is less than one ${ }^{[2]}$. The real interest rate affects velocity of money negatively while real effective exchange rate affects velocity of money positively. Again the paper found that, after 2003 from non-parametric locally weighted least square estimation smoothing method, the velocity of money increased at decreasing rate providing information that money supplied to the economy was much less than product produced and transacted in the economy. This shows tight or prudent monetary policy in Ethiopia. In general, this result suggested that, the policy to encourage sustainable economic growth and increase in interest rate would be beneficial to reduce velocity of money.

\section{References}

[1] Chiaromonte.F. "ocally weighted least square regression smoothing methods lecture notes." Michigan University, 2005.

[2] Fry, Maxwell J. "Money and Capital or Financial Deepening in Economic Development." Journal of Money, Credit, and Banking, 1988.

[3] Gujarati. "Introduction to Econometrics." Oxford University press, 2003.
[4] Honda, Zhan and Thomas. "The Federal Democratic Republic of Ethiopia: Selected Issues, International Monetary Fund." International Monetary Fund, 2008.

[5] Howells, Iris Biefang-Frisancho Mariscal and Peter. "Income and Transactions Velocities in the UK." Centre for Global Finance Working Paper Series, 2010.

[6] Khan, Rana Ejaz and Ali. "Velocity of money in pakistan; Time series analysis." 2013.

[7] Mishkin, Frederic S. The economics of money, banking, and financial markets. Addison-Wesley: The Addison-Wesley series in economics), 2004.

[8] Orphanides, Athanasios and Richard D. Porter. "P* Revisited: Money-Based Inflation Forecasts with a Changing Equilibrium Velocity." Journal of Economics and Business, 2000: 52, 87-100.

[9] Rashid, Abid. "Determinants of income velocity of money in Pakistan." International Conference on Applied Economics, 2015.

[10] Rencher, Alvin C.,. "Linear models in statistics." Bruce Schaalje. 2nd ed., 1974.

[11] Selden, R.T. "Monetary Velocity in the United States, Studies in the Quantity Theory of Money." Chicago university, 1956.

[12] Stefanski, Antonio Mele and Radoslaw. "Velocity in the Long Run: Money and Structural Transformation." School of Economics and Finance Discussion, 2016.

[13] Van den Ingh, H. "Velocity as an Indicator for Economic Policy." Erasmus School of Economics, Erasmus University Rotterdam, 2009. 